\title{
Duration of Veno-Arterial Extracorporeal Membrane and Mortality in Postcardiotomy Cardiogenic Shock
}

Giovanni Mariscalco ${ }^{1}$, Zein El-Dean ${ }^{2}$, Tomas Fux ${ }^{3}$, Angelo Dell'Aquila ${ }^{4}$, Kristjan Jonsson ${ }^{5}$, Sigurdur Ragnarsson ${ }^{6}$, Antonio Fiore ${ }^{7}$, Magnus Dalen ${ }^{8}$, Dario Di Perna ${ }^{9}$, Giuseppe Gatti ${ }^{10}$, Tatu Juvonen ${ }^{11}$, Svante Zipfel ${ }^{12}$, Andrea Perrotti ${ }^{13}$, Karl Bounder ${ }^{14}$, Khalid Alkhamees ${ }^{15}$, Antonio Loforte ${ }^{16}$, Andrea Lechiancole ${ }^{17}$, Marek Pol ${ }^{18}$, Cristiano Spadaccio ${ }^{19}$, Matteo Pettinari $^{20}$, Dieter De Keyzer ${ }^{21}$, Henryk Welp ${ }^{20}$, Daniele Maselli ${ }^{22}$, Artur Lichtenberg ${ }^{23}$, Vito Ruggieri ${ }^{24}$, and Fausto Biancari ${ }^{25}$

${ }^{1}$ Department of Surgical Sciences, Varese University Hospital, University of Insubria

${ }^{2}$ Glenfield Hospital

${ }^{3}$ Karolinska Institute

${ }^{4}$ University Hospital Münster

${ }^{5}$ Sahlgrenska University Hospital

${ }^{6}$ Lund University

${ }^{7}$ Henri Mondor Hospital Department of Orthopedic and Traumatological Surgery

${ }^{8}$ Karolinska University Hospital

${ }^{9} 7$ Division of Cardiothoracic and Vascular Surgery, Robert Debré University Hospital

${ }^{10}$ Ospedali Riuniti and University of Trieste

${ }^{11}$ Oulu University Hospital

${ }^{12}$ Hamburg University Heart Centre

${ }^{13}$ Centre Hospitalier Universitaire de Besancon

${ }^{14}$ Hopital Pontchaillou

${ }^{15}$ Prince Sultan Cardiac Center Al Hassa

${ }^{16}$ S. Orsola-Malpighi Hospital, Bologna University

${ }^{17}$ University Hospital of Udine

${ }^{18}$ PRAGUE INSTITUTE Jazykova skola

${ }^{19}$ Golden Jubilee National Hospital

${ }^{20}$ Affiliation not available

${ }^{21}$ Ziekenhuis Oost-Limburg

${ }^{22}$ St. Anna Hospital

${ }^{23}$ Universitätsklinikum Düsseldorf

${ }^{24}$ Centre Hospitalier Universitaire de Reims

${ }^{25}$ TYKS

April 28, 2020

Abstract
Background and Aim: The optimal duration of veno-arterial extracorporeal membrane oxygenation (VA-ECMO) in patients 
affected by postcardiotomy cardiogenic shock (PCS) remains controversial. We aimed to investigate the impact of VA-ECMO duration on hospital outcomes. Methods: Data on PCS patients receiving VA-ECMO were retrieved from the multicentre PC-ECMO registry. Patients were stratified according to different duration of VA-ECMO therapy: [?]3 days, 4-7 days, 8-10 days, and $>10$ days. Results: A total of 725 patients with a mean age of $62.9 \pm 12.9$ years were included. The mean duration of VA-ECMO was $7.1 \pm 6.3$ days (range: 0-39 days), and $39.4 \%$ patients were supported for [?]3 days, $29.1 \%$ for $4-7$ days, $15.3 \%$ for 8-10 days, and finally $20.7 \%$ for $>10$ days. A total of 391 (53.9\%) patients were successfully weaned from VA-ECMO while 134 $(34.3 \%)$ died prior to discharge. Multivariable logistic regression showed that prolonged duration of VA-ECMO therapy (4-7 days, adjusted rate $53.6 \%$, odds ratio [OR] 0.28, 95\% confidence interval [CI] 0.18-0.44; 8-10 days, adjusted rate $61.3 \%$,OR 0.51 , 95\% CI 0.29-0.87; and >10 days, adjusted rate 59.3\%,OR 0.49, 95\% CI 0.31-0.81) was associated with lower risk of mortality compared with VA-ECMO lasting [?]3 days (adjusted rate 78.3\%). Patients requiring VA-ECMO therapy for 8-10 days (OR 1.96, 95\% CI 1.15-3.33) and >10 days (OR 1.85, 95\% CI 1.14-3.02) had significantly higher mortality compared to those on VA-ECMO for 4-7 days. Conclusions: PCS patients weaned from VA-ECMO after 4 to 7 days of support had significantly lower mortality compared with those with shorter or longer mechanical support.

\section{Introduction}

In patients affected by postcardiotomy cardiogenic shock (PCS) following cardiac surgery, the use of venoarterial extracorporeal membrane oxygenation (VA-ECMO) has increased steadily in the last decades [1-3]. However, the complications and mortality rates associated with this mechanical support remain high [1-5]. In this context, prolonged VA-ECMO support with the risk of ECMO-induced complications is inversely associated with cardiopulmonary recovery and survival [1,3-5]. However, the optimal duration of VA-ECMO remains controversial, and the available evidence in PCS patients is limited [1,3,4-9]. We report the results of the large multicentre "Postcardiotomy Veno-arterial Extracorporeal Membrane Oxygenation" (PC-ECMO) study, analysing the impact of VA-ECMO duration on hospital mortality and early complications.

\section{Material and Methods}

\section{Patient population, Study Design and Outcome Measures}

The PC-ECMO registry is a multicenter observational study enrolling patients undergoing VA-ECMO following adult cardiac surgery at 19 centers from Belgium, Czech Republic, Finland, France, Germany, Italy, Saudi Araba, Sweden, and the United Kingdom from January 2010 to March 2018. The present study is registered in Clinicaltrials.gov (Identifier: NCT03508505), and its detailed protocol with definition criteria have been previously published [5]. Briefly, patients aged [?]18 years who required VA-ECMO for PCS following cardiac surgery were included. Exclusion criteria encompassed patients with preoperative VA-ECMO, patients with descending thoracic aorta repair, or those receiving VA-ECMO after implantation of ventricular assist device or heart transplantation. Patients without baseline data on arterial lactate level at the start of VA-ECMO were also excluded from the present analysis because of its impact on patient outcome. The primary end-point was in-hospital mortality. The study complies with the Strengthening the Reporting of Observational Studies in Epidemiology reporting requirements for observational studies (Supplemental Table 1) [10].

\section{Statistical analysis}

Statistical analysis was performed using the SPSS statistical software v. 25.0 (IBM Corporation, Armonk, NY, USA), and Stata v. 15.1 (StataCorp LLC, College Station, Texas, USA). Covariates and outcomes were reported as counts and percentages, and as mean and standard deviation or median and interquartile range (IQR). The Kruskal-Wallis test and the linear-by-linear association test were used for univariate analysis. The risk-adjusted mortality rates over different VA-ECMO interval durations were estimated using the direct standardization method employing thedstdize module of Stata, and the patient population were stratified according to different duration of VA-ECMO therapy: [?]3 days, 4-7 days, 8-10 days, and $>10$ days [3,7]. The impact of VA-ECMO duration on hospital mortality was also adjusted for the PC-ECMO score [4], multiple covariates and participating centers in logistic regression analysis. A $P<.05$ was set for statistical significance. 


\section{Results}

Among the 781 patients of the PC-ECMO registry, 56 patients (7.2\%) were excluded from the present analysis because of lack of data on arterial lactate levels before starting VA-ECMO support. A total of 725 patients over 2378 days of VA-ECMO were included in the final analysis. Their mean age was $62.9 \pm 12.9$ years (range: 18.4-86.7 years), and $232(32.0 \%)$ were female. The mean duration of VA-ECMO was $7.1 \pm 6.3$ days (median: 5.0 days; range: $0-39$ days), and $39.4 \%$ patients were supported for [?]3 days, $29.1 \%$ for $4-7$ days, $15.3 \%$ for 8-10 days, and $20.7 \%$ for $>10$ days (Figure 1 ). The different groups of VA-ECMO duration exhibited similar baseline, demographic and operative characteristics (Table 1). However, VA-ECMO duration [?]3 days was associated with a higher metabolic derangement, as expressed by the arterial lactate level before VA-ECMO institution ( $8.2+-5.4$ vs $6.5+-4.3$ vs $6.1+-4.0$ vs $6.1+-4.0, P<.0001)$ (Figure 2 ).

A total of 391 (53.9\%) patients were successfully weaned from VA-ECMO and, among those, 134 (34.3\%) died prior to discharge. Hospital survival increased from $8.1 \%$ on day 1 to $55 \%$ on day 5 . Multivariable logistic regression adjusted for the PC-ECMO score and participating centers showed that prolonged duration of VA-ECMO therapy (4-7 days, adjusted rate $53.6 \%$, odds ratio [OR] $0.28,95 \%$ confidence interval [CI] $0.18-0.44 ; 8-10$ days, adjusted rate $61.3 \%$, OR $0.51,95 \%$ CI $0.29-0.87$; and $>10$ days, adjusted rate $59.3 \%$, OR $0.49,95 \%$ CI $0.31-0.81$ ) was associated with a lower risk of mortality compared with VA-ECMO lasting [?]3 days (adjusted rate 78.3\%) (Figure 3).

However, patients requiring VA-ECMO therapy for 8-10 days (adjusted OR 1.955, 95\% CI 1.149-3.326) and $>10$ days (adjusted OR 1.854, 95\%CI 1.139-3.020) had a significantly increased risk of hospital mortality compared to those who were on VA-ECMO therapy for 4-7 days. In addition, VA-ECMO support longer than 7 days was associated with a significantly increased risk of re-exploration for bleeding, blood transfusion requirements, renal failure requiring renal replacement therapy, deep sternal wound infection, bloodstream infection and pneumonia (Table 2).

\section{Discussion}

Our data showed that in patients affected by PCS following cardiac surgery, the duration of VA-ECMO support is associated with increased mortality. Patients weaned from VA-ECMO after 4 to 7 days had significantly lower mortality compared with patients with shorter or longer mechanical support, even when adjusted for confounding. In addition, VA-ECMO support longer than 7 days was associated with a significantly increased risk of complications, including re-exploration for bleeding, blood transfusion, renal failure requiring renal replacement therapy, deep sternal wound infection, bloodstream infection and pneumonia.

Evidence from the Extracorporeal Life Support Organisation (ELSO) registry also showed that short duration of VA-ECMO is associated with high mortality. In this large registry that included 2699 VA-ECMO patients, survival increased up to day 4 and then decreased from day 4 to 12, with no significant change thereafter [1]. However, the study encompassed a mixed cohort of patients with only a minority of them undergone cardiac surgery, a limitation shared with previous studies [1-3,8,9]. On the other hand, the absence of clear guidelines on VA-ECMO weaning is the testament that this aspect is still poorly addressed [1-3]. In addition, data on survival with longer VA-ECMO runs are limited $[1,3,4,9]$. To our knowledge, the present analysis is the largest to date in evaluating the impact of VA-ECMO duration in adult patients affected by PCS following cardiac surgery. Distelmaier et al. [4] firstly addressed the impact of VA-ECMO duration on survival in 354 cardiovascular surgery patients, observing that longer VA-ECMO runs were associated with higher mortality even 2-years after hospital discharge [4]. More recently, Wang et al. [3] enrolled 166 PCS patients following coronary bypass surgery. More than $60 \%$ of patients received VA-ECMO for 3-6 days and had significantly lower mortality than those who were supported by VA-ECMO for $<3$ days or [?] 7 days [3].

Our data are consonant with previous studies, suggesting that in PCS patients following cardiac surgery VA-ECMO support longer than 7 days can be challenged, considering the associated early and late higher mortality. In this cohort of patients, the risks of complications appear to overcome the cardiopulmonary advantage exerted by the VA-ECMO support. Bloodstream infections have been demonstrated to be associated with longer VA-ECMO runs, occurring in $27.7 \%$ of treated patients $[11,12]$. Therefore, it is not 
surprising that longer VA-ECMO runs are associated with a higher risk of bloodstream infection along with an increased rate of blood transfusions and organ failure [11,12]. Among other complications, administration of large volumes of blood transfusion and renal failure requiring renal replacement therapy are potentially fatal conditions in longer VA-ECMO runs, particularly in PCS patients with an underlying severe cardiac dysfunction $[13,14]$. Similarly, our data confirmed that shorter VA-ECMO runs ([?]3 days) are also associated with significantly higher mortality. Although we did not detect a higher rate of lethal haemorrhage in this patient group that has been previously suggested as main cause of the increased early mortality $[15,16]$, the underlying primary cardiac condition seemed to play a major role in the survival of those patients $[3,17]$. Cardiopulmonary failure leading to multiorgan failure appeared to predominate over ECMO treatment. The hyperlactatemia observed in patients under VA-ECMO [?]3 days suggest a significant metabolic derangement in these patients. In this context, arterial lactate level may be useful in guiding the appropriate timing of VA-ECMO discontinuation, thereby avoiding futile prolonged support [19].

The results observed in our series are relevant considering the unsolved issue of balancing a fruitful VAECMO duration against a vain support especially in light of the uniquely high level of resources involved [19]. In addition, due to the lack of defined guidelines and indications, the duration of ECMO support is often based on arbitrary limits [1]. Data derived from ELSO registry over a 10-year period indicates that $52 \%$ of patients on VA-ECMO are discontinued from support because of irreversible organ failure [1]. Therefore, when cardiopulmonary recovery cannot be successfully achieved within 7 days, other therapeutic options should be considered, including ventricular assist device implantation or heart transplantation $[1,7,19]$.

Certainly, our study is not exempted from limitations. First, our series is subjected to the limitations of all observational analyses, including selection bias and unmeasured confounding. Second, the present analysis is conditional to in-hospital survival only, and our data do not allow an assessment of the outcomes after weaning and discharge from the hospital. Third, a trend in the survival of patients with very long ECMO duration (> 15 days) may not be fully detected due to the small number of remaining individuals, with insufficient statistical power. Lastly, we cannot account for the surgeon and anaesthetist's experience as well as for the differences in local policies of ECMO weaning. Despite these limitations, our cohort is currently the largest in evaluating the impact of VA-ECMO duration in the PCS setting.

In conclusion, in PCS following cardiac surgery, patients weaned from VA-ECMO after 4 to 7 days of support had significantly lower mortality compared with those with shorter or longer mechanical support. The present data can contribute to identifying the most ideal duration of VA-ECMO support, supporting clinicians in deriving more accurate prognostic models and timely weaning strategies.

\section{Disclosures}

The investigators have no conflicts of interest to disclose.

\section{*Collaborators}

Susan Dashey, FRCA; Hakeem Yusuff, FRCA; Richard Porter, FRCA; Caroline Sampson, FRCA; Chris Harvey, FRCA.

Department of Cardiovascular Surgery and Anaesthesia and Critical Care, Glenfield Hospital, University Hospitals of Leicester NHS Trust, Leicester, United Kingdom

\section{Alessandro Di Cesare, MD}

Division of Cardiothoracic and Vascular Surgery, Robert Debre University Hospital, Reims, France

\section{Anders Jeppsson, MD, PhD}

Department of Cardiac Surgery, Sahlgrenska University Hospital, Gothenburg, Sweden

\section{Marco Gabrielli, MD}

Division of Cardiac Surgery, Ospedali Riuniti, Trieste, Italy 


\section{Daniel Reichart, MD}

Hamburg University Heart Center, Hamburg, Germany

Sidney Chocron, MD

Department of Thoracic and Cardio-Vascular Surgery, University Hospital Jean Minjoz, Besancon, France

Mariafrancesca Fiorentino, MD

Department of Cardiothoracic, Transplantation and Vascular Surgery, S. Orsola Hospital, University of Bologna, Bologna, Italy

\section{Ugolini Livi, MD}

Cardiothoracic Department, University Hospital of Udine, Udine, Italy

Ivan Netuka, MD

Institute of Clinical and Experimental Medicine, Prague, Czech Republic

Maarten Strauven, MD

Department of Cardiovascular Surgery, Ziekenhuis Oost-Limburg, Genk, Belgium

\section{Kristiina Palve, MD}

Heart Center, Turku University Hospital and University of Turku, Turku, Finland.

Diyar Saeed, MD

Cardiovascular Surgery, University Hospital of Duesseldorf, Dusseldorf, Germany

\section{Author contributions}

Biancari and Mariscalco, had full access to all of the data in the study and take responsibility for the integrity of the data and the accuracy of the data analysis.

Study concept and design: Biancari, Mariscalco, Dalen, De Keyzer, El-Dean, Fiore, Loforte, Spadaccio.

Acquisition of data: Alkhamees, Biancari, Bounaderm, Dalen, Dell'Aquila, Di Perna, El-Dean, Fiore, Gatti, Lichtenberg, Jonsson, Lechiancole, Loforte, Mariscalco, Perrotti, Pettinari, Pol, Ragnarsson, Ruggieri, Saeed, Spadaccio, Welp, Zipfel.

Analysis and interpretation of data: Biancari, Mariscalco, Maselli.

Drafting of the manuscript: Biancari, Mariscalco, El-Dean, Maselli.

Critical revision of the manuscript for important intellectual content: Alkhamees, Biancari, Dalen, Dell'Aquila, De Keyzer, Di Perna, Fiore, Gatti, Lichtenberg, Jonsson, Lechiancole, Loforte, Mariscalco, Maselli, Perrotti, Pettinari, Pol, Ragnarsson, Reichart, Ruggieri, Saeed, Settembre, Spadaccio, Welp, Zipfel.

Paper supervision: Biancari, Mariscalco, Juvonen.

Statistical analysis: Biancari, Mariscalco.

Language revision: El-Dean.

\section{References}

1. Smith M, Vukomanovic A, Brodie D, Thiagarajan R, Rycus P, Buscher H. Duration of veno-arterial extracorporeal life support (VA ECMO) and outcome: an analysis of the Extracorporeal Life Support Organization (ELSO) registry. Crit Care . 2017 Mar 6;21:45. 
2. Becher PM, Twerenbold R, Schrage B, et al. Risk prediction of in-hospital mortality in patients with venoarterial extracorporeal membrane oxygenation for cardiopulmonary support: The ECMOACCEPTS score. J Crit Care . 2020;56:100-105.

3. Wang L, Yang F, Wang X, Xie H, Fan E, Ogino M, Brodie D, Wang H, Hou X. Predicting mortality in patients undergoing VA-ECMO after coronary artery bypass grafting: the REMEMBER score. Crit Care. 2019 Jan 11;23:11.

4. Distelmaier K, Wiedemann D, Binder C, et al. Duration of extracorporeal membrane oxygenation support and survival in cardiovascular surgery patients. J Thorac Cardiovasc Surg . 2018;155:24712476.

5. Biancari F, Dalen M, Fiore A, et al. Multicenter study on postcardiotomy venoarterial extracorporeal membrane oxygenation.J Thorac Cardiovasc Surg. 2020;159:1844-1854.

6. Mariscalco G, Salsano A, Fiore A, et al. Peripheral versus central extracorporeal membrane oxygenation for postcardiotomy shock: Multicenter registry, systematic review, and meta-analysis. $J$ Thorac Cardiovasc Surg . 2019 Oct 31. pii: S0022-5223(19)32376-1.

7. Gupta P, Robertson MJ, Beam B, et al. Relationship of ECMO duration with outcomes after pediatric cardiac surgery: a multi-institutional analysis. Minerva Anestesiol. 2015;81:619-27

8. Staudacher DL, Bode C, Wengenmayer T. Duration of extracorporeal membrane oxygenation is a poor predictor of hospital survival. J Crit Care . 2016;32:207-8.

9. Guenther SP, Shudo Y, Hiesinger W, Banerjee D. Prolonged veno-arterial extracorporeal life support for cardiac failure. Int J Artif Organs . 2018;41:437-444.

10. von Elm E, Altman DG, Egger M, Pocock SJ, Gotzsche PC, Vandenbroucke JP; STROBE Initiative. The Strengthening the Reporting of Observational Studies in Epidemiology (STROBE) statement: guidelines for reporting observational studies. Lancet. 2007;370:1453-7.

11. Kim DW, Yeo HJ, Yoon SH, Lee SE, Lee SJ, Cho WH. Impact of bloodstream infections on catheter colonization during extracorporeal membrane oxygenation. J Artif Organ. 2016;19:128-133.

12. Menaker J, Galvagno S, Rabinowitz R, et al. Epidemiology of blood stream infection in adult extracorporeal membrane oxygenation patients: A cohort study. Heart Lung. 2019;48:236-239.

13. Roubinian N. TACO and TRALI: biology, risk factors, and prevention strategies. Hematol Am Soc Hematol Educ Program. 2018;2018:585-94.

14. Murphy GJ, Reeves BC, Rogers CA, Rizvi SI, Culliford L, Angelini GD. Increased mortality, postoperative morbidity, and cost after red blood cell transfusion in patients having cardiac surgery. Circulation. 2007;116:2544-52.

15. Zangrillo A, Landoni G, Biondi-Zoccai G, et al. A meta-analysis of complications and mortality of extracorporeal membrane oxygenation. Crit Care Resusc. 2013;15:172-8.

16. Smith A, Hardison D, Bridges B, Pietsch J. Red blood cell transfusion volume and mortality among patients receiving extracorporeal membrane oxygenation. Perfusion. 2013;28:54-60.

17. Mariscalco G, Salsano A, Fiore A, et al. Peripheral versus central extracorporeal membrane oxygenation for postcardiotomy shock: Multicenter registry, systematic review, and meta-analysis. $J$ Thorac Cardiovasc Surg. 2019 Oct 31. pii: S0022-5223(19)32376-1.

18. Biancari F, Fiore A, Jonsson K, et al. Prognostic significance of arterial lactate levels at weaning from postcardiotomy venoarterial extracorporeal membrane oxygenation. J Clin Med . 2019;8(12).

19. Mulaikal TA, Nakagawa S, Prager KM. Extracorporeal membrane oxygenation bridge to no recovery. Circulation.2019;139:428-430.

Table 1. Baseline and operative data.

\begin{tabular}{|c|c|c|c|c|c|}
\hline Outcomes & $\begin{array}{l}\text { VA-ECMO } \\
\text { duration }\end{array}$ & $\begin{array}{l}\text { VA-ECMO } \\
\text { duration }\end{array}$ & $\begin{array}{l}\text { VA-ECMO } \\
\text { duration }\end{array}$ & $\begin{array}{l}\text { VA-ECMO } \\
\text { duration }\end{array}$ & $\begin{array}{l}\text { VA-ECMO } \\
\text { duration }\end{array}$ \\
\hline & $\begin{array}{l}{[?] 3 \text { days } 253} \\
\text { pts }\end{array}$ & $\begin{array}{l}\text { 4-7 days } 211 \\
\text { pts }\end{array}$ & $\begin{array}{l}\text { 8-10 days } 111 \\
\text { pts }\end{array}$ & $\begin{array}{l}>10 \text { days } 150 \\
\text { pts }\end{array}$ & $P$-values \\
\hline $\begin{array}{l}\text { Baseline } \\
\text { characteristics }\end{array}$ & $\begin{array}{l}\text { Baseline } \\
\text { characteristics }\end{array}$ & $\begin{array}{l}\text { Baseline } \\
\text { characteristics }\end{array}$ & $\begin{array}{l}\text { Baseline } \\
\text { characteristics }\end{array}$ & $\begin{array}{l}\text { Baseline } \\
\text { characteristics }\end{array}$ & $\begin{array}{l}\text { Baseline } \\
\text { characteristics }\end{array}$ \\
\hline
\end{tabular}




\begin{tabular}{|c|c|c|c|c|c|}
\hline Outcomes & $\begin{array}{l}\text { VA-ECMO } \\
\text { duration }\end{array}$ & $\begin{array}{l}\text { VA-ECMO } \\
\text { duration }\end{array}$ & $\begin{array}{l}\text { VA-ECMO } \\
\text { duration }\end{array}$ & $\begin{array}{l}\text { VA-ECMO } \\
\text { duration }\end{array}$ & $\begin{array}{l}\text { VA-ECMO } \\
\text { duration }\end{array}$ \\
\hline$\overline{\text { Age (years) }}$ & $64.1 \pm 12.3$ & $62.6 \pm 13.1$ & $63.3 \pm 11.9$ & $61.1 \pm 14.2$ & 0.23 \\
\hline Female & $82(32.4)$ & $61(28.9)$ & $40(36.0)$ & $49(32.7)$ & 0.70 \\
\hline $\begin{array}{l}\text { Body mass } \\
\text { index }\left(\mathrm{kg} / \mathrm{m}^{2}\right)\end{array}$ & $27 \pm 5$ & $27 \pm 5$ & $27 \pm 5$ & $28 \pm 6$ & 0.86 \\
\hline $\begin{array}{l}\text { eGFR } \\
(\mathrm{mL} / \mathrm{min} / 1.73 \\
\left.\mathrm{m}^{2}\right)\end{array}$ & $67 \pm 29$ & $70 \pm 33$ & $70 \pm 31$ & $68 \pm 29$ & 0.47 \\
\hline $\begin{array}{l}\text { Haemoglobin } \\
(\mathrm{g} / \mathrm{L})\end{array}$ & $125 \pm 21$ & $126 \pm 20$ & $128 \pm 25$ & $123 \pm 23$ & 0.39 \\
\hline Dialysis & $13(5.2)$ & $8(3.8)$ & $3(2.7)$ & $7(4.7)$ & 0.65 \\
\hline Diabetes & $55(21.7)$ & $46(21.8)$ & $32(28.8)$ & $46(30.7)$ & 0.023 \\
\hline $\begin{array}{l}\text { Coronary } \\
\text { artery disease }\end{array}$ & $110(43.5)$ & $97(46.0)$ & $47(42.3)$ & $65(43.3)$ & 0.87 \\
\hline Stroke & $21(8.3)$ & $16(7.6)$ & $6(5.4)$ & $11(7.3)$ & 0.55 \\
\hline $\begin{array}{l}\text { Extracardiac } \\
\text { arteriopathy }\end{array}$ & $44(17.4)$ & $38(18.0)$ & $14(12.6)$ & $12(8.0)$ & 0.007 \\
\hline $\begin{array}{l}\text { Pulmonary } \\
\text { disease }\end{array}$ & $39(15.4)$ & $28(13.3)$ & $15(13.5)$ & $21(14.0)$ & 0.68 \\
\hline $\begin{array}{l}\text { Atrial } \\
\text { fibrillation }\end{array}$ & $60(23.7)$ & $52(24.6)$ & $31(27.9)$ & $34(22.7)$ & 0.97 \\
\hline $\begin{array}{l}\text { Prior cardiac } \\
\text { surgery }\end{array}$ & $65(25.7)$ & $44(20.9)$ & $25(22.5)$ & $43(28.7)$ & 0.57 \\
\hline $\begin{array}{l}\text { Prior } \\
\text { myocardial } \\
\text { infarction }\end{array}$ & $79(31.2)$ & $70(33.2)$ & $44(39.6)$ & $53(35.3)$ & 0.23 \\
\hline LVEF [?]50\% & $140(55.3)$ & $129(61.1)$ & $62(56.9)$ & $95(63.3)$ & 0.18 \\
\hline $\begin{array}{l}\text { Active } \\
\text { endocarditis }\end{array}$ & $36(14.2)$ & $25(11.8)$ & $10(9.0)$ & $12(8.0)$ & 0.039 \\
\hline $\begin{array}{l}\text { Type A aortic } \\
\text { dissection }\end{array}$ & $32(12.6)$ & $10(4.7)$ & $8(7.2)$ & $7(4.7)$ & 0.006 \\
\hline $\begin{array}{l}\text { Emergency } \\
\text { procedure }\end{array}$ & $77(30.4)$ & $53(25.1)$ & $29(26.1)$ & $43(28.7)$ & 0.66 \\
\hline $\begin{array}{l}\text { Critical } \\
\text { preoperative } \\
\text { state }\end{array}$ & $84(33.2)$ & $77(36.5)$ & $38(34.2)$ & $59(39.3)$ & 0.28 \\
\hline $\begin{array}{l}\text { Preoperative } \\
\text { stroke/unconscic }\end{array}$ & $\begin{array}{l}14(5.5) \\
\text { ness }\end{array}$ & $5(2.4)$ & $2(1.8)$ & $5(3.3)$ & 0.18 \\
\hline $\begin{array}{l}\text { PC-ECMO } \\
\text { score }^{\mathrm{a}}\end{array}$ & $4.5 \pm 2.5$ & $3.7 \pm 32.4$ & $3.7 \pm 2.4$ & $3.6 \pm 2.2$ & $<0.0001$ \\
\hline $\begin{array}{l}\text { EuroSCORE } \\
\text { II, score }(\%)\end{array}$ & $16.6 \pm 18.2$ & $16.4 \pm 18.5$ & $11.9 \pm 11.9$ & $15.7 \pm 17.8$ & 0.48 \\
\hline Operative data & Operative data & Operative data & Operative data & Operative data & Operative data \\
\hline $\begin{array}{l}\text { ACC time } \\
\text { (minutes) }\end{array}$ & $140 \pm 137$ & $120 \pm 73$ & $117 \pm 87$ & $131 \pm 86$ & 0.07 \\
\hline $\begin{array}{l}\text { CPB time } \\
\text { (minutes) }\end{array}$ & $248 \pm 133$ & $209 \pm 113$ & $192 \pm 112$ & $233 \pm 123$ & $<0.0001$ \\
\hline $\begin{array}{l}\text { Coronary } \\
\text { surgery }\end{array}$ & $127(50.2)$ & $101(47.9)$ & $55(49.5)$ & $70(46.7)$ & 0.56 \\
\hline
\end{tabular}




\begin{tabular}{llllll}
\hline Outcomes & $\begin{array}{l}\text { VA-ECMO } \\
\text { duration }\end{array}$ & $\begin{array}{l}\text { VA-ECMO } \\
\text { duration }\end{array}$ & $\begin{array}{l}\text { VA-ECMO } \\
\text { duration }\end{array}$ & $\begin{array}{l}\text { VA-ECMO } \\
\text { duration }\end{array}$ & $\begin{array}{l}\text { VA-ECMO } \\
\text { duration }\end{array}$ \\
\hline $\begin{array}{l}\text { Aortic } \\
\text { procedures }\end{array}$ & $62(24.5)$ & $37(17.5)$ & $18(16.2)$ & $29(19.3)$ & 0.15 \\
$\begin{array}{l}\text { Aortic valve } \\
\text { replacement/repair }\end{array}$ & $76(30.0)$ & $62(29.4)$ & $30(27.0)$ & $39(26.0)$ & 0.34 \\
$\begin{array}{l}\text { Mitral valve } \\
\text { surgery }\end{array}$ & $84(33.2)$ & $83(39.3)$ & $32(28.8)$ & $52(34.7)$ & 0.85 \\
$\begin{array}{l}\text { Tricuspid } \\
\text { valve surgery }\end{array}$ & $29(11.5)$ & $26(12.3)$ & $22(19.8)$ & $15(10.0)$ & 0.77 \\
$\begin{array}{l}\text { Other major } \\
\text { procedures }\end{array}$ & $21(8.3)$ & $18(8.5)$ & $11(9.9)$ & $20(13.3)$ & 0.10 \\
$\begin{array}{l}\text { VA-ECMO } \\
\text { inserted }\end{array}$ & $161(63.6)$ & $119(56.4)$ & $68(61.3)$ & $87(58.0)$ & 0.36 \\
$\begin{array}{l}\text { immediately } \\
\text { after surgery }\end{array}$ & & & & \\
$\begin{array}{l}\text { Central } \\
\text { arterial } \\
\text { cannulation }\end{array}$ & $84(33.2)$ & $64(30.3)$ & $32(28.8)$ & $43(28.7)$ & 0.30 \\
$\begin{array}{l}\text { Arterial } \\
\text { lactate before }\end{array}$ & $8.2 \pm 5.4$ & $6.5 \pm 4.3$ & $6.1 \pm 4.0$ & $6.1 \pm 4.0$ & $<0.0001$ \\
$\begin{array}{l}\text { VA-ECMO, } \\
\text { mmol/L }\end{array}$ & & & & \\
\hline
\end{tabular}

Note : Continuous data are presented as mean \pm standard deviation; categorical variables as number (percent).

Abbreviations: ACC, aortic cross clamp; CPB, cardiopulmonary bypass; eGFR, estimated glomerular filtration rate; LVEF, left ventricular ejection fraction; VA-ECMO, veno-arterial extracorporeal membrane oxygenation.

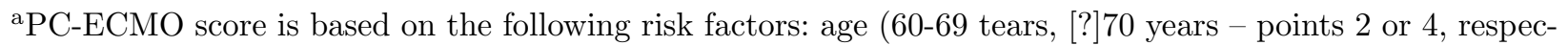
tively), female gender (points 1), prior cardiac surgery (points 1), arterial lactate [?]6 mmol/L (points 2), aortic arch surgery (points 4), and preoperative stroke/unconsciousness (points 5) [please see ref. 5].

Table 3. In-hospital outcomes.

\begin{tabular}{llllll}
\hline Outcomes & $\begin{array}{l}\text { VA-ECMO } \\
\text { duration }\end{array}$ & $\begin{array}{l}\text { VA-ECMO } \\
\text { duration }\end{array}$ & $\begin{array}{l}\text { VA-ECMO } \\
\text { duration }\end{array}$ & $\begin{array}{l}\text { VA-ECMO } \\
\text { duration }\end{array}$ & $\begin{array}{l}\text { VA-ECMO } \\
\text { duration }\end{array}$ \\
\hline $\begin{array}{l}{[?] \mathbf{3} \text { days } \mathbf{2 5 3}} \\
\text { pts }\end{array}$ & $\begin{array}{l}\mathbf{4 - 7} \text { days } \mathbf{2 1 1} \\
\text { pts }\end{array}$ & $\begin{array}{l}\mathbf{8 - 1 0} \text { days } \mathbf{1 1 1} \\
\text { pts }\end{array}$ & $\begin{array}{l}\mathbf{> 1 0} \text { days } \mathbf{1 5 0} \\
\mathbf{p t s}\end{array}$ & $P$-values \\
$\begin{array}{l}\text { Hospital } \\
\text { mortality }\end{array}$ & $198(78.3)$ & $113(53.6)$ & $68(61.3)$ & $89(59.3)$ & $<0.0001$ \\
$\begin{array}{l}\text { Mortality on } \\
\begin{array}{l}\text { VA-ECMO } \\
\text { Heart trans- }\end{array}\end{array}$ & $175(69.2)$ & $67(31.8)$ & $43(38.7)$ & $49(32.7)$ & $<0.0001$ \\
$\begin{array}{l}\text { plantation or } \\
\text { VAD }\end{array}$ & $3(1.2)$ & $7(3.3)$ & $6(5.4)$ & $9(6.0)$ & 0.005 \\
$\begin{array}{l}\text { Stroke/global } \\
\text { brain ischemia }\end{array}$ & $36(14.2)$ & $50(23.8)$ & $27(24.3)$ & $27(18.1)$ & 0.22 \\
New dialysis & $100(40.5)$ & $106(51.0)$ & $68(61.3)$ & $103(71.0)$ & $<0.0001$
\end{tabular}




\begin{tabular}{llllll}
\hline Outcomes & $\begin{array}{l}\text { VA-ECMO } \\
\text { duration }\end{array}$ & $\begin{array}{l}\text { VA-ECMO } \\
\text { duration }\end{array}$ & $\begin{array}{l}\text { VA-ECMO } \\
\text { duration }\end{array}$ & $\begin{array}{l}\text { VA-ECMO } \\
\text { duration }\end{array}$ & $\begin{array}{l}\text { VA-ECMO } \\
\text { duration }\end{array}$ \\
\hline $\begin{array}{l}\text { Pneumonia } \\
\text { Deep sternal }\end{array}$ & $53(20.9)$ & $77(36.5)$ & $49(44.1)$ & $87(58.0)$ & $<0.0001$ \\
$\begin{array}{l}\text { wound } \\
\text { infection }\end{array}$ & $2(0.8)$ & $6(2.8)$ & $3(2.7)$ & $15(10.0)$ & $<0.0001$ \\
$\begin{array}{l}\text { Blood stream } \\
\text { infection }\end{array}$ & $35(13.8)$ & $52(24.6)$ & $34(30.6)$ & $54(36.0)$ & $<0.0001$ \\
$\begin{array}{l}\text { Reoperation } \\
\text { for } \\
\text { intrathoracic } \\
\text { bleeding/tamponade }\end{array}$ & $95(37.5)$ & $82(39.0)$ & $48(43.2)$ & $82(54.7)$ & $<0.0001$ \\
$\begin{array}{l}\text { RBC } \\
\text { transfusion }>\end{array}$ & $158(62.5)$ & $139(65.9)$ & $77(69.4)$ & $121(80.7)$ & $<0.0001$ \\
$\begin{array}{l}\text { lo units } \\
\text { RBC units } \\
\text { transfused } \\
\begin{array}{l}\text { (units) } \\
\text { Intensive care }\end{array}\end{array}$ & $16.6 \pm 14.9$ & $21.0 \pm 21.0$ & $22.6 \pm 18.5$ & $34.4 \pm 27.9$ & $<0.0001$ \\
$\begin{array}{l}\text { unit stay } \\
\text { (days) }\end{array}$ & $7.1 \pm 10.8$ & $19.5 \pm 20.4$ & $21.3 \pm 19.3$ & $28.4 \pm 17.7$ & $<0.0001$ \\
$\begin{array}{l}\text { Hospital stay } \\
\text { (days) }\end{array}$ & $9.3 \pm 13.5$ & $30.0 \pm 32.4$ & $32.6 \pm 37.2$ & $40.6 \pm 38.9$ & $<0.0001$ \\
\hline
\end{tabular}

Note : Continuous data are presented as mean \pm standard deviation; categorical variables as number (percent).

Abbreviations: RBC, red blood cell; VAD, ventricular assist device; VA-ECMO, veno-arterial extracorporeal membrane oxygenation.

Figure legend

Figure 1. Number of patients who died and survived to hospital discharge according to the duration of postcardiotomy VA-ECMO.

Figure 2. Medial lactate level at the start, during and at weaning from VA-ECMO. $P$-values are from Kruskal-Wallis' test. Data is from 409 patients with complete data on arterial lactate.

Figure 3. Risk-adjusted hospital and on VA-ECMO mortality rates according to the duration of postcardiotomy VA-ECMO.

Supplemental Table I. STROBE Statement for observational studies.

\begin{tabular}{|c|c|c|}
\hline & Item No & Recommendation \\
\hline Title and abstract & 1 & $\begin{array}{l}\text { (a) Indicate the study's design with a commonly used term in the title } \\
\text { (b) Provide in the abstract an informative and balanced summary of wl }\end{array}$ \\
\hline Introduction & Introduction & Introduction \\
\hline Background/rationale & 2 & Explain the scientific background and rationale for the investigation bei \\
\hline Objectives & 3 & State specific objectives, including any prespecified hypotheses \\
\hline Methods & Methods & Methods \\
\hline Study design & 4 & Present key elements of study design early in the paper \\
\hline Setting & 5 & Describe the setting, locations, and relevant dates, including periods of \\
\hline
\end{tabular}




\begin{tabular}{|c|c|c|}
\hline & Item No & Recommendation \\
\hline Participants & 6 & (a) Give the eligibility criteria, and the sources and methods of selectio \\
\hline Variables & 7 & Clearly define all outcomes, exposures, predictors, potential confounder \\
\hline Data sources/ measurement & $8^{*}$ & For each variable of interest, give sources of data and details of methods \\
\hline Bias & 9 & Describe any efforts to address potential sources of bias \\
\hline Study size & 10 & Explain how the study size was arrived at \\
\hline Quantitative variables & 11 & Explain how quantitative variables were handled in the analyses. If app \\
\hline Statistical methods & 12 & $\begin{array}{l}\text { (a) Describe all statistical methods, including those used to control for } \\
\text { (b) Describe any methods used to examine subgroups and interactions } \\
\text { (c) Explain how missing data were addressed } \\
\text { (d) If applicable, describe analytical methods taking account of samplin } \\
\text { (e) Describe any sensitivity analyses }\end{array}$ \\
\hline Results & Results & Results \\
\hline Participants & $13^{*}$ & $\begin{array}{l}\text { (a) Report numbers of individuals at each stage of study - eg numbers } 1 \\
\text { (b) Give reasons for non-participation at each stage } \\
\text { (c) Consider use of a flow diagram }\end{array}$ \\
\hline Descriptive data & $14^{*}$ & $\begin{array}{l}\text { (a) Give characteristics of study participants (eg demographic, clinical, } \\
\text { (b) Indicate number of participants with missing data for each variable }\end{array}$ \\
\hline Outcome data & $15^{*}$ & Report numbers of outcome events or summary measures \\
\hline Main results & 16 & $\begin{array}{l}\text { (a) Give unadjusted estimates and, if applicable, confounder-adjusted e } \\
\text { (b) Report category boundaries when continuous variables were categor } \\
\text { (c) If relevant, consider translating estimates of relative risk into absolu }\end{array}$ \\
\hline Other analyses & 17 & Report other analyses done e.g. analyses of subgroups and interaction \\
\hline Discussion & Discussion & Discussion \\
\hline Key results & 18 & Summarise key results with reference to study objectives \\
\hline Limitations & 19 & Discuss limitations of the study, taking into account sources of potentia \\
\hline Interpretation & 20 & Give a cautious overall interpretation of results considering objectives, \\
\hline Generalisability & 21 & Discuss the generalisability (external validity) of the study results \\
\hline Other information & Other information & Other information \\
\hline Funding & 22 & Give the source of funding and the role of the funders for the present \\
\hline
\end{tabular}

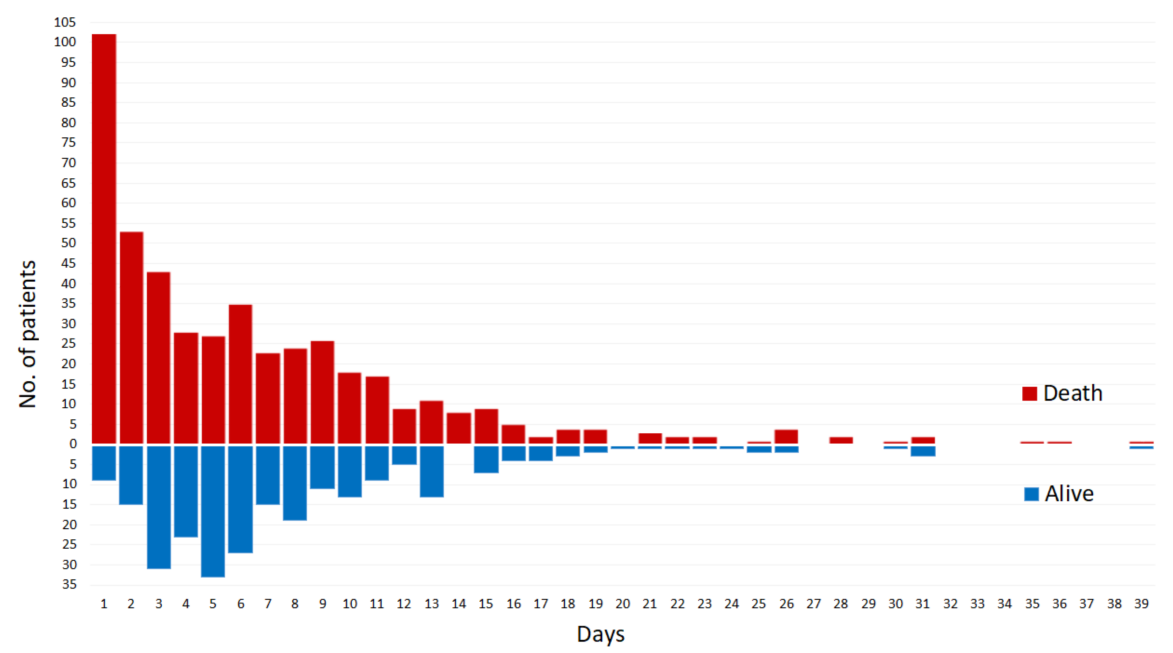



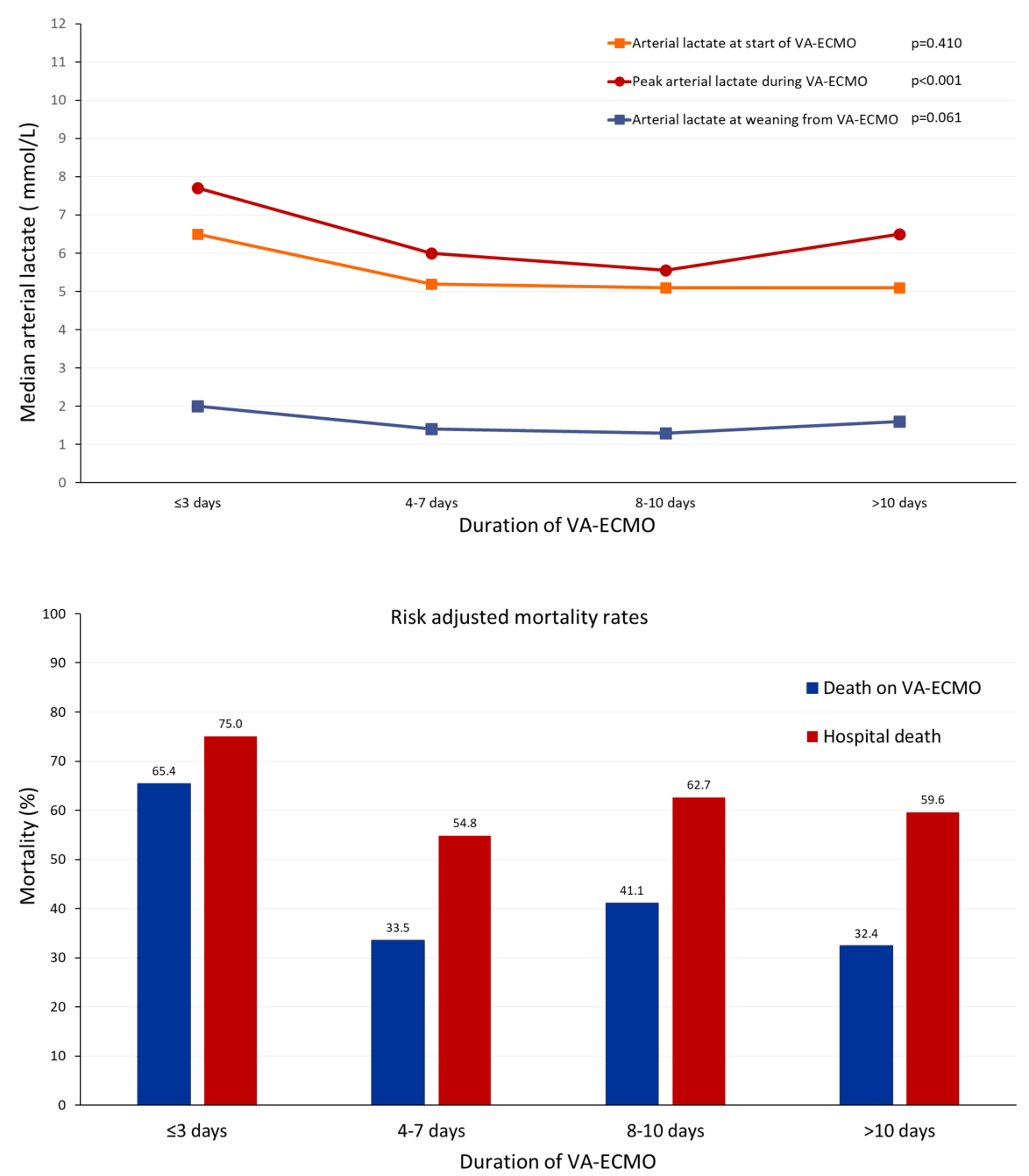